九州大学学術情報リポジトリ

Kyushu University Institutional Repository

\title{
Chaetomium spp., antagonistic microorganisms to phytopathogenic fungi
}

Nakashima, Nobuhiko

Phytopathological Laboratory, Faculty of Agriculture, Kyusyu University

Moromizato, Zenichi

Phytopathological Laboratory, College of Agriculture, University of the Ryukyus

Matsuyama, Nobuaki

Phytopathological Laboratory, Faculty of Agriculture, Kyusyu University

https://doi.org/10.5109/23975

出版情報：九州大学大学院農学研究院紀要. 36 (1/2)，pp. 109-115，1991-10. Kyushu University バージョン：

権利関係 : 


\title{
Chaetomium spp., antagonistic microorganisms to phytopathogenic fungi
}

\author{
Nobuhiko Nakashima*, Zenichi Moromizato** and Nobuaki M atsuyama* \\ * Phytopathological Laboratory, Faculty of Agriculture, \\ Kyusyu University 46-01, Fukuoka 812, Japan \\ * * Phytopathological Laboratory, College of Agriculture, \\ University of the Ryukyus, Okinawa 903-01, Japan
}

(Received July 24, 1991)

\begin{abstract}
Ten isolates of Chaetomium spp. were obtained from sclerotia of Sclerotinia sclerotior. $u m$ buried in the soil in Okinawa prefecture. Since eight of ten isolates inhibited mycelial growth of S. sclerotionum on PDA medium, their identification was undertaken. These isolates had small perithecia and arcuate terminal hairs. Since seven of eight isolates had two apical germpores in ascospore and the tips of terminal hairs coiled $\mathbf{1} \sim 2$ times, they were identified as C. trilaterale var. diponum. Other isolates were identified as C. trilaterale var. cupreum because of one apical germpore in ascospore and red-copper terminal hairs. The antifungal substance $\left(\mathrm{C}_{31} \mathrm{H}_{35} \mathrm{O}_{8} \mathrm{~N}\right)$ produced by $\mathrm{C}$. trilaterale var. diponum $R C-5$ inhibited mycelial growth of S. sclerotiorum more than $90 \%$ in PD liquid medium at $0.5 \mathrm{ppm}$.
\end{abstract}

\section{INTRODUCTION}

Chaetomium spp. are known as one of the important member of pyrenomycetidae. They are saprophytic fungi which degrade cellulose containing substances. Since the first report on the antibacterial substance, chetomin, produced by C. cochliodes (Waksman and Bugie, 1944), various biologically active substances produced by Chaetomium spp., such as, cochliodinol (Brewer et al., 1968), colletodiol (Powell, 1969), oosporein (Cole, 1974) and chaetoglobosin (Sekita et al., 1981) have been reported. Some of them were inhibitive against plant pathogens. Cullen and Andrews (1984) reported that chetomin produced by C. globosum showed a principal antagonism to Venturia inaequalis.

In 1986, one of the author, Moromizato, obtained ten isolates of Chaetomium spp. which had small perithecia with arcuate terminal hairs by trapping with sclerotia of Sclerotinia sclerotiorum buried in the soil in Okinawa prefecture. Eight of ten isolates inhibited mycelial growth of S. sclerotiorum intensively on PDA (potato dextrose agar) plate (Fig. 1).

It was reported that the microorganisms such as Gliocladium spp., Trichoderma spp. and Coniothyrium minitans (Willetts and Wong, 1980) were antagonistic by degrading sclerotia in soil. While, the isolates of Chaetomium spp. studied in this experiment seemed to be antagonistic by inhibiting the mycelial growth. Therefore, the excretion of the antifungal substance by the present isolates was assumed. The extraction and the purification were successfully conducted and the results were reported elsewhere (Nakashima et al., 1991). The results of identification on the isolates of Chaetomium spp. tested and the biological effects of the excreted antifungal substance against S. sclerotiorum will be presented in this report. 


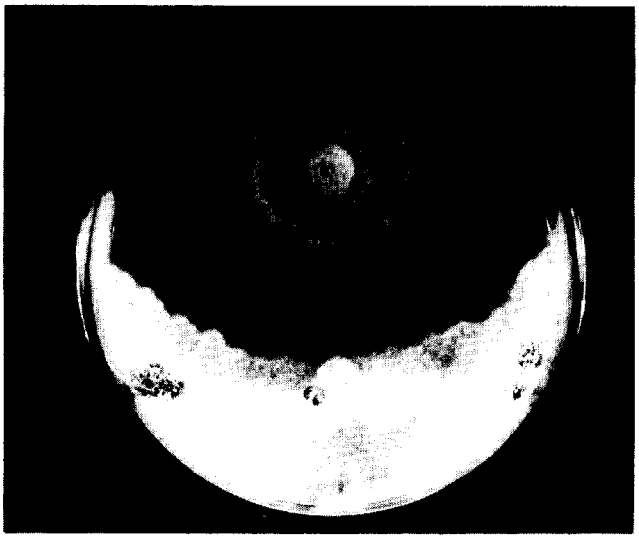

Fig. 1. Inhibition of mycelial growth of Sclerotinia sclerotionum by Chaetomium trilaterale var. diporum on PDA medium.

\section{MATERIALS AND METHODS}

\section{Fungal isolates}

Chaetomium spp. used in this study were obtained from sclerotia of Sclerotinia sclerotiorum buried in the soil in Okinawa prefecture (Moromizato et al., 1987). Eight of ten isolates $(\mathrm{RC}-1,2,3, \mathbf{5}, \mathbf{6}, \mathbf{8}, \mathbf{9}, \mathbf{1 0})$ except for two $(\mathrm{RC}-4,7)$ inhibited mycelial growth of S. sclerotionum intensively on PDA medium.

\section{Media used for identification.}

Isolate RC-5 was grown on PDA $(1,000 \mathrm{ml}$ potato $(300 \mathrm{~g})$ decoction, $20.0 \mathrm{~g} \mathrm{D}$ glucose, $15.0 \mathrm{~g}$ agar), cellulose agar (CA) (10.0 g cellulose powder, $0.5 \mathrm{~g} \mathrm{NH}_{4} \mathrm{NO}_{3}, 0.5 \mathrm{~g}$ $\mathrm{K}_{2} \mathrm{HPO}_{4}, 0.5 \mathrm{~g} \mathrm{MgSO}_{4} \cdot 7 \mathrm{H}_{2} \mathrm{O}, 20.0 \mathrm{~g}$ agar, $1,000 \mathrm{ml}$ distilled water), corn meal agar (CMA) (17.0 g corn meal agar (Difco), 1,000 ml distilled water), Oat meal agar (OMA) (50.0 g oat meal powder, $20.0 \mathrm{~g}$ sucrose, $15.0 \mathrm{~g}$ agar, $1,000 \mathrm{ml}$ distilled water) and malt extract agar (MEA) (20.0 g malt extract, $18.0 \mathrm{~g}$ agar, $1,000 \mathrm{ml}$ distilled water) media, and other isolates were cultured on PDA, CA, and CMA medium at $27^{\circ} \mathrm{C}$ until mature perithecia were formed. Then, their morphological characteristics were observed. Since the ascus of Chaetomium spp. was extinguished in mature perithecium, the observation of ascus was conducted before maturation.

\section{Production and extraction of the antifungal substance}

The isolate RC-5 was used for production of the antifungal substance. Mycelial disk (7 $\mathrm{mm}$ in diameter) cut from the mycelial mat on PDA with cork borer was inoculated to modified Richards medium (20.0 g D-glucose, $10.0 \mathrm{~g} \mathrm{KNO}_{3}, 5.0 \mathrm{~g} \mathrm{KH}_{2} \mathrm{PO}_{4}$, $2.5 \mathrm{~g} \mathrm{MgSO}_{4} \cdot 7 \mathrm{H}_{2} \mathrm{O}, 20 \mathrm{mg} \mathrm{FeCl}_{3} \cdot 6 \mathrm{H}_{2} \mathrm{O}, 1 \mathrm{mg}$ thiamine hydrochloride, $0.05 \mathrm{mg}$ biotin, $1,000 \mathrm{ml}$ distilled water, $\mathrm{pH}$ 5.2).

The culture was conducted at $30^{\circ} \mathrm{C}$ for 10 days in still condition. The antifungal substance was extracted with chloroform and purified by thin layer chromatography \{dichloromethane-methanol-28\% ammonia water $(65: 30: 5, \mathrm{v} / \mathrm{v})$ \}, reextractions with 
chloroform and recrystallization with hexane from chloroform solution. Details were presented elsewhere (Nakashima et al., 1991).

\section{Mycelial growth inhibition of S. sclerotiorum in PD liquid medium}

The mycelial disk $(7 \mathrm{~mm})$ of $S$. sclerotionum precultured on PDA plate was inoculated in $30 \mathrm{ml}$ potato dextrose (PD) liquid medium containing $0.5 \mathrm{ppm}$ of the antifungal substance. The culture was incubated at $22^{\circ} \mathrm{C}$ and filtrated through filter paper in suction. Mycelia transferred in a weighing bottle was dried at $60^{\circ} \mathrm{C}$ and weighed.

Effect of the antifungal substance on ascospore germination of S. sclerotiorurn

Sclerotia were harvested from PDA culture incubated at $22^{\circ} \mathrm{C}$ for 21 days. Harvested sclerotia were germinated by the methods of Saito (1977). Obtained expanded-apothecia were picked up with forceps and pressed in a drop of sterilized distilled water on sterilized slide glass. Concentrated ascospore suspension was recovered with micro-pipette and dropped in 0.1-10 ppm sample solution. Sterilized distilled water was used as the check. The test suspension was kept at $22^{\circ} \mathrm{C}$ and germinated ascospores were counted at 24th hour.

\section{RESULTS AND DISCUSSION}

The seven isolates (RC-1, 3, 5, 6, 8, 9, 10) which had intensive antifungal activity against S. sclerotiorum on PDA plate were seemed to be the same species. These isolates produced reddish pigment in PDA medium and sometimes red exudate was observed on the mycelial mat. Perithecia were dark olive brown in transmitted light, subspherical to ovoid, 90-140 $\times 80-140 \mu \mathrm{m}$ with wide ostiole. Terminal hairs were yellowish brown in transmitted light, straight or arcuate, at the tips often coiled 1-2 times, 3.5-4.5 $\mu \mathrm{m}$ wide at the base. Lateral hairs were straight or arcuate. Asci were clavate and 8 spores. Ascospores were olive brown to olive green, oblate to irregularly ovate, sometimes flattened on one side, 8.5-10.5 $\times 4.5-5.5 \mu \mathrm{m}$, terminal germ pore at each end (Fig. 2).

These morphological characteristics indicated that these fungi belong to Chuetomium aureum or C. trilaterale because of their arcuate terminal hairs, small perithecia, and two apical germ pores (Millner, 1975 ; Millner et al., 1977 ; Skolko, 1953 ; Udagawa, 1960). Ames (1969) reported that terminal hairs of C. aureum were not coiled. While, terminal hairs of these isolates were coiled 1-2 times at the tips. From these results the isolates were decided as C. trilaterale. Cooke (1973) reported that C. trilaterale could be classified into four varieties, namely, var. trilaterale, var. chiversii, var. cupreum and var. diporum. C. trilaterale var. trilaterale had subglobose perithecia but present isolates had comparatively ovate perithecia. Ascospores of $\mathrm{C}$. trilaterale var. chiversii had single germ pore but these isolates had two apical germ pores. The color of terminal hairs of C. trilaterale var. cupreum was bright orangecopper but these isolates had yellowish brown terminal hairs. These results finally led the conclusion that the present isolates were C. trilaterale Chivers var. diporum Cooke.

The isolate RC-2 was distinguished from other isolates by the color of perithecia 


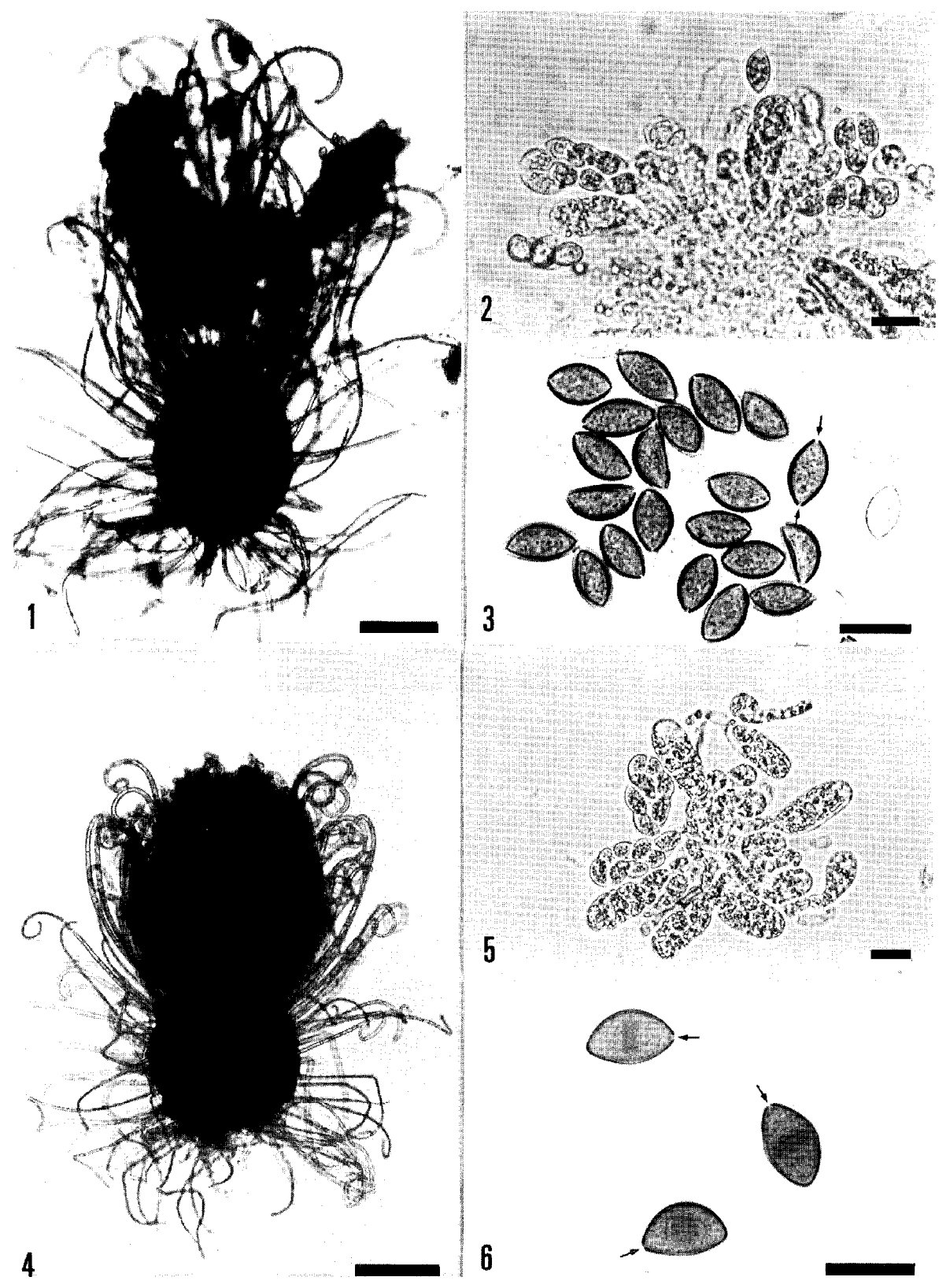

Fig. 2. Photomicrographs of Chaetomium trilaterale var. diporum $\mathrm{RC}-5(1,2,3)$ and C.trilaterale var. cupreum $\mathrm{RC}-2(4,5,6)$.

1, 4: Perithecium (scale bar $=50 \mu \mathrm{m}$ ). 2, 5: Ascus (scale bar $=10 \mu \mathrm{m}$ ).

3, 6: Ascospore (scale bar $=10 \mu \mathrm{m}$ ). Arrows show germpores. 
formed on CA and CMA medium. The perithecia were dark red in reflected light. Morphological characteristics of $\mathrm{RC}-2$ were different from var. diporum in the color of terminal hair and germ pore of ascospore. This isolate had bright orange-copper terminal hair coiled regularly 2-3 times at the tips and single apical germ pore (Fig. 2). These characteristics indicated that the isolate RC-2 belongs to C. trilaterale Chivers var. cupreum (Ames) Cooke.

Von Arx et al. (1986) published the monograph of Chaetomium and proposed C. aureum for C. trilaterale var. diporum and C. cupreum for C. trilaterale var. cupreum.

The new concept of von Arx et al., however, has not been discussed enough, we undertook the identification by the description of Cooke.

The results of mycelial growth inhibition of S. sclerotionum were shown in Fig. 3. There were no significant differences at 48 hours, but mycelial dry weight was suppressed more than $90 \%$ by 156th hour. While, the antifungal substance did not inhibit ascospore germination of S. sclerotiorum even at $10 \mathrm{ppm}$ (Table 1). From these results, it was indicated that the antifungal substance produced by Chaetomium trilaterale var. diporum had mycelial-growth inhibition activity but not sporegermination inhibition activity.

The novel antifungal substance produced by Chaetomium trilaterale var. diporum $R C-5$ was decided as $\mathrm{C}_{31} \mathrm{H}_{35} \mathrm{O}_{8} \mathrm{~N}$ and the details will be presented elsewhere (Naka. shima et al., 1991). The chemical structure and mode of action of the antifungal

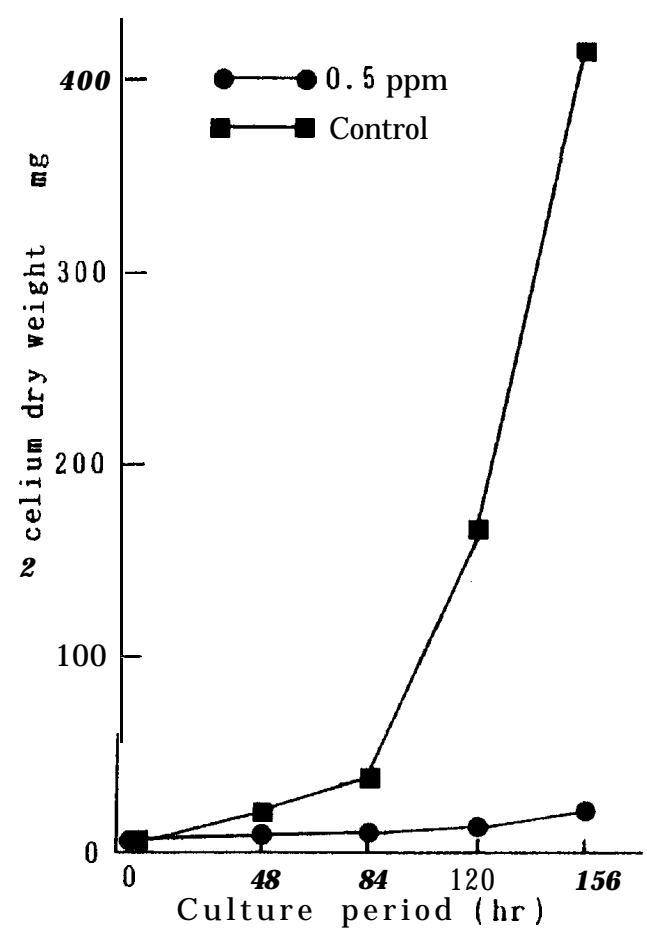

Fig. 3. Effect of antifungal substance on mycelial growth in liquid medium (PD). 
Table 1. Effect of the antifungal substance against ascospore germination of S. sclerotiorum

\begin{tabular}{cc}
\hline \hline Concentration & $\begin{array}{l}\text { Percentage of germinated } \\
\text { ascospore }\end{array}$ \\
\hline 0. lppm & $94.7^{\text {a) }}$ \\
2. Oppm & 96.5 \\
5. Oppm & 92.6 \\
10. Oppm & 94.8 \\
Control & 93.2 \\
\hline
\end{tabular}

a) Germinated ascospores were counted at 24 hours after the treatment

substance are the subject of future study.

\section{ACKNOWLEDGEMENTS}

The authors are grateful to Dr. S. Udagawa in National Institute of Hygienic Sciences for his many advices at the identification of Chaetomium spp., Prof. E. Taniguchi, Department of Agricultural Chemistry in Kyushu University for his many advices, and Mr. R. Isobe, Faculty of Pharmaceutical Sciences for performing the FAB- MS.

\section{REFERENCES}

Adams, P. B. and W. A. Ayers 1979 Ecology of Sclerotinia species. Phytopathology, 69 : 896-899

Ames, L. M. 1969 A monograph of the Chaetomiaceae. (reprint) J. Cramer, New York.

Brewer, D., W. A. Jerram and A. Taylor 1968 The production of cochliodinol and a related metabolite by Chaetomium species. Can. J.Microbiol., $14: 861-866$

Cole, R. J., J. W. Kirksey, H. G. Cutler and E. E. Davis 1974 Toxic effect of oosporein from Chaetomium trilaterale.J.Agr. Food Chem., 22 : 517-520

Cooke, J. C. 1973 Variation in isolates of Chaetomium trilaterale. Mycologia, 65 : 1212-1220

Cullen, D. and J. H. Andrews 1984 Evidence for the role of antibiosis in the antagonism of Chaetomium globosum to the apple scab pathogen, Venturia inaequalis. Can. J. Bot., 62 : 18191823

Lloyd, G., A. Robertson, G. B. Sankey and W. B. Whalley 1955 The chemistry of fungi. Part XXV. Oosporein, a metabolite of Chaetomium aureum Chivers. J. Chem. Soc.,2163-2165

Millner, P. D. 1975 Ascomycetes of Pakistan : Chaetomium. Biologia, 21: 39-73

Millner, P. D., J. J. Motta and P. L. Lents 1977 Ascospores, germ pores, ultrastructure, and thermophilism of Chaetomium. Mycologia, $69: 720-733$

Moromizato, Z., N. Matsuyama and M. Tamori 1987 Chaetomium species isolated from sclerotia of Sclerotinia sclerotiorum buried in soil and those antifungal ability. Ann. Phytopath, Soc. Japan., $53: 415$ (Abstr. in Japanese)

Nakashima, N., Z. Moromizato and N. Matsuyama 1991 The antifungal substance produced by Chaetomium trilaterale var. diporum $\mathrm{RC}-5$ isolated from sclerotia of Sclerotinia sclerotiorum. Ann. Phytopath. Soc. Japan, 57 : in press

Powell, J. W. and W. B. Whalley 1969 The chemistry of fungi. Part LVIII. Structure of colletodiol, a metabolite of Chaetomium funicola. J. Chem. Soc., (C) 911-912

Saito, I. 1977 Studies on the maturation and germination of sclerotia of Sclerotinia sclerotiorum 
(Lib.) de Bary, a causal fungus of bean stem rot. Rep. Hokkaido Prefect, Agric.Exp. Stn., 26: 1 $-107$

Sekita, S., H. Yoshihira, S. Natori, S. Udagawa, T. Muroi, Y. Sugiyama, H. Kurata and M. Umeda 1981 Mycotoxin production by Chaetomium spp. and related fungi. Can. J. Microbiol., 27:766772

Skolko, A. J. and J. W. Groves 1953 Notes on seed-borne fungi VII. Chaetomium. Can. J. Bot., 31 : 779- 809

Udagawa, S, 1960 A taxonomic study on the Japanese species of Chaetomium. J.Gen. Appl. Microbiol., $6: 223-251$

von Arx, J. A., J. Guarro and M. J. Figueras 1986 The ascomycete genus Chaetomium. Bei.Nora Hedwigia, 84: 1-162

Waksman S. A. and E. Bugie 1944 Chetomin a new antibiotic substance produced by Chaetomium cochliodes. J. Bacteriol., 48 : 527-536

Willets, H. J. and J. A. L. Wong 1980 The biology of Sclerotinia sclerotionum. S. trifolionum and S. minor with emphasis on specific nomenclature. Botanical Review, $46: 102-165$ 